\title{
Novel adsorption model of filtration process in polycarbonate track-etched membrane: Comparative study
}

\author{
Asma Adda ${ }^{1,2^{\dagger}}$, Salah Hanini ${ }^{1}$, Mohamed Abbas ${ }^{2}$, Meriem Sediri ${ }^{1}$ \\ ${ }^{1}$ Laboratory of Biomaterials and Transport Phenomena (LBMPT), Faculty of Science and Technology, University of Dr Yahia fares Medea, Algeria \\ ${ }^{2}$ Unit of Solar Equipments Development-UDES/EPST CDER, Head of Research Department: Cooling Systems and Water Treatment using Renewable \\ Energies-FTEER, Tipaza, Algeria
}

\begin{abstract}
Current assumptions are used in the formulation of pseudo-first (PFO) and second-order (PSO) models to describe the kinetic data of filtration based on ideal operating conditions. This paper presents a new model developed with pseudo $n^{\text {th }}$ order and based on real assumption. A comparison was performed between PFO, PSO and the new model to highlight their performance and the optimisation of the pseudo-order equation, using MATLAB software. Adsorption characteristic of bovine serum albumin adsorption on the track-etched membrane are used as a medium based on protein filtration data were extracted from the literature for different concentrations to demonstrate the comparison between PFO/PSO and the new model. The pseudo first and second-order kinetic models were applied to test the experimental data and they did not provide reasonable values. The results show that the predicted values are consistent with experimental values giving a good correlation coefficient $R^{2}=0.997$ and a minimum root mean squared error RMSE $=0.0171$. Indeed, the experimental results follow the new model and the optimal pseudo equation order $n=1.115$, the most suitable curves for the new model. As a result, we used different experimental adsorption data from the literature to examine and check the applicability and validity of the model.
\end{abstract}

Keywords: Adsorption, Bovine serum albumin, Membrane filtration, Modelling

\section{Introduction}

The development of membrane technology has been considerably expanded in many areas, particularly in food industry, water reuse and effluent treatment. Membrane fouling by protein is an inevitable phenomenon and one of the real obstacles which reduce the performance of the filtration process. Consequently, the control and the anticipation of fouling are required for the proper management of the operation.

According to Karros et al. [1], membrane fouling is a complex phenomenon that can be irreversible with solute adsorption, which is characterised by the blocking of membrane pores during filtration by the combination retention, accumulation, and adsorption of particles and compounds on the membrane or in the membrane's pores. This phenomenon is the basis of a physical, chemical and biological nature, which leads to a decrease of both permeability and a variation in selectivity [2, 3].
In recent years, the adsorption property of microfiltration membrane proteins is used as an indicator of membrane performance [4]. The kinetic development of adsorption requires a knowledge and understanding of the complexity of its mechanisms. Several models have been developed to predict the expression rate of the adsorption mechanisms [5]. Most research in this field report experimental results about the adsorption capacity of solutes at equilibrium and about the kinetics of adsorption. The data are then described using various models or empirical formulas.

In the literature, two types of equations have been commonly used to represent the kinetics. Pseudo-first-order (PFO) and pseudo-second-order (PSO) models are the two most adopted empirical models in liquid adsorption studies [6].

Pseudo first-order kinetic was initially proposed at the end of the 19th century by Lagergren [7]. PSO kinetic was introduced in the middle of the 80 's $[8,9]$.
This is an Open Access article distributed under the terms of the Creative Commons Attribution Non-Commercial License (http://creativecommons.org/licenses/by-nc/3.0/) which permits unrestricted non-commercial use, distribution, and reproduction in any medium, provided the original work is properly cited.

Copyright (C) 2020 Korean Society of Environmental Engineers
Received April 4, 2019 Accepted July 6, 2019

${ }^{\dagger}$ Corresponding author

Email: a.docsolaire2017@gmail.com

Tel: +21-377-443-5070

ORCID: 0000-0003-2487-7563 
Later, Ho [10] showed that PSO equation could be presented in four linear forms with a very different least squares regression analysis, thus different obtained constants. However, Ho concluded that the best fit kinetic parameters should be obtained using a nonlinear method.

Following Ho's work, other researchers [11, 12] have shown that it is practical to predict adsorption kinetics as well as the best linearization technique for the most suitable kinetic model. Though, it is not an appropriate fit kinetic method.

However, the nonlinear technique curve fitting of PSO and PFO equations needs to be solved by trial and error [10], while it will be an appropriate method in the prediction of the adsorption kinetic.

Furthermore, in addition to a first and second precise pseudo-order (PFO and PSO), a new approach has been developed based on the diffusion equation, which has proven to be an excellent quantitative prediction agreement [13]. Simonin [14] also examined a comparison of pseudo- first-order and PSO rate laws for the description of liquid/solid adsorption kinetics where the pseudosecond-order reaction kinetics provides the best correlation of experimental data.

More recently, four research studies have shown that an error in the use of a pseudo- first-order kinetic model requires correction [15-18]. Moreover, Tseng and Wu [19] proposed a convenient method to determine kinetic parameters of adsorption processes by nonlinear regression of the PFO, PSO and pseudo-nth-order (PNO) equations with SigmaPlot 11 software. They have provided the best fit kinetic parameters of PNO equations which allow describing the adsorption process better than using traditional equation (PFO/PSO). Of these articles, some demonstrated that the PSO equation suitably fitted their experimental data, and some further showed that PSO equation is more reasonable than PFO equation.

Recently, many studies based on the adsorption of bovine serum albumin (BSA) on a porous polyethylene membrane, have been proposed as an improvement of a simple physical model [20]. The PSO kinetic model is the most favoured, applicable and relevant kinetic model compared to the first-order pseudo kinetic model for the adsorption behaviour of BSA [21-23]. As a result it is difficult to correlate adsorption data with variables by simple mathematical modelling. Therefore, an artificial neural network (ANN) offers an advantageous tool [24, 25].

$\mathrm{Fu}$ and $\mathrm{Xu}$ [26] have improved an artificial back-propagation neural network (BP-ANN) successfully used to model the adsorption of BSA on a porous polyethylene membrane.

This paper presents a new model to determine the kinetic parameters of the non-linear regression adsorption process. However, a non-linear regression of the pseudo- first-order, pseudo- second-order and model equation was performed and an optimisation of the pseudo-order $\mathrm{n}$ was performed using the MATLAB software. In addition, adsorption characteristic curves were plotted to highlight the differences between the PFO, PSO and the new model equations. This model is used to describe the parameters of adsorption correlation of BSA solution using polycarbonate track-etched (PCTE) membrane media. These kinetic data were provided to investigate the applicability and validity of the proposed model. Minimum root mean square error and least linear - squares $\left(R^{2}\right)$ were used to indicate the most appropriate order.

The utility of the model is not limited to the prediction of the experimental data chosen for model validation. In addition, its predictive capacity and the validity of the proposal should also allow the model parameters for other experiments and measurements to be studied and estimated from correlations.

\section{Methodology}

\subsection{Kinetic Study}

In order to investigate and demonstrate the absorption of BSA solution using PCTE membrane media, a new model has been established to predict the adsorption kinetic process. In addition, a comparative study was carried out with the Pseudo First and Second Order equations using the experimental data reported by Ho and Zydney. Ho and Zydney [27] conducted an experiment of measurement and test samples of suspensions with different concentrations ranging from 0.5 to $5 \mathrm{~g} / \mathrm{L}$, under different pressures. Experimental data has been summarised in Table 1.

Table 1. Experimental Conditions Reported by Ho and Zydney [27]

\begin{tabular}{llc}
\hline Media membrane & GE polycarbonate track etched membrane \\
& Pore diameter & $0.2 \mu \mathrm{m}$ \\
& Normal thickness & $10 \mu \mathrm{m}$ \\
& Porosity & 0.14 \\
& BSA solutions of \\
Suspensions & concentration 0.5, 1.0, 1.4, 2.0, 5.0 g/L \\
Operating pressure & $0.8,2.0,4.0,8.0 \mathrm{Psi}$
\end{tabular}

As a result, the ability of the proposed model to describe the experimental kinetic data was evaluated by adjusting this rate law to the experimental data. In addition, the values were obtained by digitalising the item numbers using Getdata. Graph. Digitizer 2.24 software.

The results summarised in Table 2 are presented in Fig. 1.

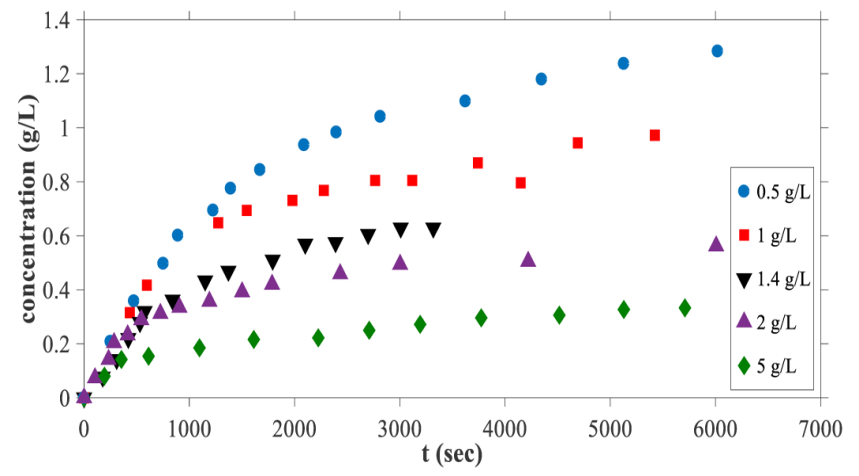

Fig. 1. Plot of filtrate volume $V$ vs time $t$ for five experiments $c=0.5 \mathrm{~g} / \mathrm{L}$, $c=1.0 \mathrm{~g} / \mathrm{L}, c=1.4 \mathrm{~g} / \mathrm{L}, c=2.0 \mathrm{~g} / \mathrm{L}$ and $c=5.0 \mathrm{~g} / \mathrm{L}$. 
Table 2. Experimental Data Extracted with Getdata. Graph. Digitizer software [28]

\begin{tabular}{|c|c|c|c|c|c|c|c|c|c|}
\hline \multicolumn{2}{|c|}{$\mathrm{C}=0.5 \mathrm{gL}^{-1}$} & \multicolumn{2}{|c|}{$\mathrm{C}=1.0 \mathrm{gL}^{-1}$} & \multicolumn{2}{|c|}{$\mathrm{C}=1.4 \mathrm{gL}^{-1}$} & \multicolumn{2}{|c|}{$\mathrm{C}=2.0 \mathrm{gL}^{-1}$} & \multicolumn{2}{|c|}{$\mathrm{C}=5.0 \mathrm{gL}^{-1}$} \\
\hline t (sec) & $\mathbf{v}\left(m^{3} m^{-2}\right)$ & t (sec) & $\mathbf{v}\left(m^{3} m^{-2}\right)$ & t (sec) & $\mathbf{v}\left(m^{3} m^{-2}\right)$ & t (sec) & $\mathbf{v}\left(m^{3} m^{-2}\right)$ & t (sec) & $\mathbf{v}\left(m^{3} m^{-2}\right)$ \\
\hline 0 & 0 & 0 & 0 & 0 & 0 & 0 & 0 & 0 & 0 \\
\hline 250.87 & 0.208 & 433.90 & 0.315 & 176.99 & 0.077 & 103.56 & 0.0737 & 193.55 & 0.080 \\
\hline 473.87 & 0.358 & 596.61 & 0.417 & 309.73 & 0,142 & 233.01 & 0.142 & 354.84 & 0.142 \\
\hline 752.61 & 0,497 & $1,274.58$ & 0.648 & 420.35 & 0.22 & 284.79 & 0.204 & 612.90 & 0.154 \\
\hline 891.98 & 0,601 & $1,545.76$ & 0.694 & 530.97 & 0.279 & 414.24 & 0.233 & $1,096.77$ & 0.185 \\
\hline $1,226.48$ & 0.694 & $1,979.66$ & 0.731 & 575.22 & 0.320 & 543.69 & 0.289 & $1,612.90$ & 0.216 \\
\hline $1,393.73$ & 0.775 & $2,277.97$ & 0.768 & 840.71 & 0.362 & 724.92 & 0.312 & $2,225.81$ & 0.222 \\
\hline $1,672.47$ & 0.844 & $2,766.10$ & 0.805 & $1,150.44$ & 0.433 & 906.15 & 0.335 & $2,709.68$ & 0.25 \\
\hline $2,090.59$ & 0.936 & $3,118.64$ & 0.805 & $1,371.68$ & 0.469 & $1,190.94$ & 0.357 & $3,193.55$ & 0.272 \\
\hline $2,397.21$ & 0.983 & $3,742.37$ & 0.87 & $1,792.04$ & 0.510 & $1,501.62$ & 0.392 & $3,774.19$ & 0.296 \\
\hline $2,815.33$ & 1.041 & $4,149.15$ & 0.796 & $2,101.77$ & 0.569 & $1,786.41$ & 0.42 & $4,516.13$ & 0.306 \\
\hline $3,623.69$ & 1.098 & $4,691.52$ & 0.944 & $2,389.38$ & 0.575 & $2,433.66$ & 0.459 & $5,129.03$ & 0.327 \\
\hline $4,348.43$ & 1.179 & $5,423.73$ & 0.9722 & $2,699.12$ & 0.605 & $3,003.24$ & 0.494 & $5,709.68$ & 0.333 \\
\hline $5,128.92$ & 1.237 & & & $3,008.85$ & 0.629 & $4,220.06$ & 0.505 & & \\
\hline $6,020.91$ & 1.283 & & & $3,318.58$ & 0.629 & $6,006.47$ & 0.562 & & \\
\hline & & & & $3,606.19$ & 0.647 & & & & \\
\hline
\end{tabular}

\subsubsection{Adsorption kinetics modelling}

A number of studies based on the pseudo and physical laws of filtration (Langmuir, Freundlich, pseudo first and second-order) exist in the literature giving incorrect results based on a hypothesis, although this hypothesis used in the formulation of filtration laws is incorrect. To overcome these errors, a new model has been proposed with pseudo $n^{\text {th }}$ order using a true hypothesis based on real conditions:

- Solid surface is not uniform;

- Adsorption heat depends on the recovery rate of the solid surface;

- Adsorption is done using two layers;

- No balance exists between the molecules of the two phases;

- Filtration can be addressed by adsorption;

- Morphological meshes of the membrane structure are equivalent to the sites;

- Fouling begins after filling the meshes;

- Physico-chemical parameters are independent of temperature and initial concentration;

According to filtration variation rate over time, it is assumed that the chemical substances present in the feed can be absorbed by the membrane and /or the cake layer and the adsorption rate can be defined by the expression pseudo order kinetic:

$$
\frac{d q}{d t}=k_{n}\left(q_{\max }-q_{t}\right)^{n}
$$

Where, $\mathrm{n}$ is the real number $\left(n \in R^{+}\right), q(t)$ is the adsorbed amount of protein per unit of membrane mass $(\mathrm{mg} / \mathrm{g}), q_{\max }$ is the maximum adsorption capacity of the membrane $(\mathrm{mg} / \mathrm{g})$ and $k_{n}$ the constant of the reaction rate $\left[(\mathrm{mg} / \mathrm{g})^{1-n} \mathrm{~s}^{-1}\right]$.

It is assumed that the removal of adsorbed substances is incomplete by an overall balance of the adsorbed mass taking into account that the mass retained by the membrane is different from the one initially present in the feed with the following result [28]:

$$
q(t) \cdot M=\delta \cdot V \cdot C_{i n}
$$

Where, $M$ is the mass of the membrane, $V$ is the cumulative filtrate volume, $C_{i n}$ is the mass concentration of the chemical substances in feed flow, and $\delta$ is the retention rate of the membrane. $(0<\delta<1)$, if $\delta=0:$ no adsorption, $\delta=1$ : total absorption Substituting Eq. (2) in Eq. (1) leads Eq. (3):

$$
\begin{gathered}
\frac{d\left(\delta \cdot V \cdot C_{i n} / M\right)}{d t}=k_{n}\left[\left(\frac{\delta \cdot V \cdot C_{i n}}{M}\right)_{\max }-\left(\frac{\delta \cdot V \cdot C_{i n}}{M}\right)_{t}\right]^{n} \\
\frac{d V_{t}}{d t}=k_{n}\left(\frac{\delta \cdot V \cdot C_{i n}}{M}\right)^{n-1} \cdot\left(V_{m}-V_{t}\right)^{n}
\end{gathered}
$$

Where:

$$
\left\{\begin{array}{l}
\frac{d V(t)}{d t}=K_{n}\left(V_{m}-V_{t}\right)^{n} \\
V_{t=0}=V(0)=0
\end{array}\right.
$$

And: $K_{n}=k_{n}\left(\frac{\delta \cdot C_{i n}}{M}\right)^{n-1}$

\subsubsection{Pseudo-first order equation}

The pseudo order $\mathrm{n}$ of Eq. (5) equal 1 is a simple kinetic analysis of adsorption; it is given by the following equation [29, 30]:

$$
V=V_{m}\left[1+e^{-k_{1} t}\right]
$$

Where, is the PFO rate constant of adsorption $\left(\mathrm{min}^{-1}\right)$ and $V_{m}$ is the filtrate volume. The constant $k_{1}$ model can be determined 
using $V$ versus $t$ plot. Fig. 2 shows a schematic representation of this variation for different concentration suspensions.

\subsubsection{Pseudo second order equation}

Where the pseudo order $n$ equal 2 (Eq. (5)), it's based on equilibrium adsorption as the following expression of the form [31]:

$$
\frac{1}{V}=\frac{1}{V_{m}}+\frac{1}{k_{2} V_{m}^{2}} \cdot \frac{1}{t}
$$

Where $k_{2}$ is the pseudo-second order rate constant $(\mathrm{kg} / \mathrm{g} \mathrm{min})$. The filtrate volume $V$ and the constant $k_{2}$ can be determined experimentally from plot $V$ versus $t$ (Fig. 3).

\subsubsection{Adsorption model}

For the $n^{t h}$ pseudo-order, the integration of Eq. (4) between the initial state $(t=0, V=0)$ and the instantaneous state $(t=t, V=V)$ is given as follows:

$$
\int_{V_{m}}^{V_{m}-V}\left(V_{m}-V\right)^{-n} d\left(V_{m}-V\right)=-\int_{0}^{t} k_{n} d t
$$

The integration solution of (7) has the following form:

$$
V=V_{m}-\left[\frac{V_{m}^{n-1}}{1+t(n-1) K_{n} V_{m}^{n-1}}\right]^{\frac{1}{n-1}}
$$

Eq. (9) is the formula of the proposed model for the adsorption process of BSA.

The proposed model verified the following boundary conditions:

$$
\lim _{t=0} V=0 \text { and } \lim _{t \rightarrow \infty} V=V_{m}
$$

Using origin8Pro software to indicate the parameters, respectively constant $K_{n}$ and the maximum filtrate volume, according to the pseudo-order $n$ and concentration $C$. The relationship allows us to write the final equation of the model.

The model will be written as follows:

\subsection{Mathematical Method}

We established a MATLAB software environment program to solve the equation and optimize the parameters and make a comparison between the proposed model and other first and second-order pseudo models. In addition, our model equation is nonlinear with multi-variables and an experimental database were solved with lsqcurvefit is appropriate to solve non-linear multi-variable problems with data base and estimate the correlation coefficient between experimental data and predicted data. Lsqcurvefit used a mathematical model based on genetic and levernberg-Marquard algorithms to determine the equation parameters $V_{m}, K_{n}$ and pseudo order $n$, respectively by nonlinear regression and give very good adjustments to the experimental data as most of their respective regression correlation coefficients $\left(R^{2}\right)$ are close to unity [31].

\subsection{Error Function}

Nonlinear regression has been developed as an important factor in designing the adsorption systems. However, recent works have shown the developing error (between the predictions and experimental data) and the model's incapacity [32].

There are many ways of measuring a model's accuracy. However, the Mean Absolute Error MAE and RESE are ones of the many metrics for assessing the quality and efficiency of a model. The best-fit model is the one with the lowest value of MAE and RMSE, both can be range from zero to infinity [31, 33].

\subsubsection{The mean absolute error (MAE)}

MAE is the average of all absolute errors; it's the difference between the experimental values and the predicted or calculated values for each instance [34] Eq. (13).

$$
M A E=\frac{1}{n} \sum_{i=1}^{n}\left|\left(Y_{i, \exp }-Y_{i, c a l}\right)\right|
$$

Where is the number of data points; $Y_{i, \exp }$ and $Y_{i, c a l}$ are referring, respectively to the experimentally and calculated values obtained from the proposed model.

$$
V(t)=(1.68276-0.58581 . n)-\left[\frac{(1.68276-0.58581 . n)^{n-1}}{1+t(n-1)\left(3.67 .10^{-8} e^{\left(\frac{n}{0.17911}\right)}+8.6468 .10^{-4}\right)(1.68276-0.58581 . n)^{n-1}}\right]^{\frac{1}{n-1}}
$$

According to the experimental data, there is an important variation of filtrate volume as a function of the concentration of adsorbed substance. In order to establish a relation between the pseudo-order of the equation and the concentration, we use the following formula Eq. (11):

$$
\begin{array}{rl}
V(t) & =V_{m}-\left[\frac{V_{m}^{\left(b 0+b 1^{*} c+b 2^{*} C^{2}\right)-1}}{1+t^{*}\left(d 0+d 1^{*} C\right) *\left(\left(b 0+b 1^{*} c+b 2^{*} C^{2}\right)-1\right) * V_{m}^{\left(b 0+b 1^{*} C+b 2^{*} C^{2}\right)-1}}\right]^{\frac{1}{\left(\left(b 0+b 1^{*} C+b 2^{*} C^{2}\right)-1\right)}} \\
n=b_{0}+b_{1}{ }^{*} C+b_{2}{ }^{*} C^{2} & k=d_{0}+d_{1}{ }^{*} C \quad b_{0}^{*}=b_{0}-1
\end{array}
$$

After the reformulation of the new model, we finally obtain Eq. (12):

$$
V(t)=V_{m}-\left[\frac{\left.V_{m}^{\left(b 0^{*}\right.}+b 1^{*} C+b 2^{*} c^{2}\right)}{1+t^{*}\left(d 0+d 1^{*} C\right) *\left(b 0^{*}+b 1^{*} C+b 2^{*} C^{2}\right)^{*} V_{m}^{\left(b 1^{*}+b 1^{*} C+b 2^{*} C^{2}\right)}}\right]^{\frac{1}{\left(b 0^{*}+b 1^{*} C+b 2^{*} C^{2}\right)}}
$$




\subsubsection{RMSE}

RMSE is a measure of performance model. It does this by measuring difference between calculated values and the experimental values, which would provide a better fit as the magnitude of the error decrease [32, 35].

$$
R M S E=\sqrt{\frac{\sum_{i=1}^{n}\left(Y_{i, \exp }-Y_{i, c a l}\right)^{2}}{n}}
$$

Where $n$ is the number of data points; $Y_{i, \exp }$ are referring to the experimental value and the $Y_{i, c a l}$ calculated values obtained from the proposed model.

\section{Results and Discussion}

\subsection{Kinetic Model Validity}

Model's validation is the critical step in the modelling process. Thus, according to Eq. (12), PFO and PSO can follow nonlinear regression with MATLAB software. The results for adsorption of BSA are illustrated in Table 3 and the nonlinear parameters are presented in Fig. 2.

A nonlinear regression with MATLAB software is performed to obtain the values of $K_{n}$ and to optimize the pseudo-order $\mathrm{n}$ from Eq. (12), when the value of filtrate volume experimental data $V$ and time $t$ is plotted. The different values of $K_{n}$ are obtained from Eq. (6), (7) and (12), respectively. For fitting the proposed model, the results of $R^{2}=0.993$ are obtained for concentration $C=1.4 \mathrm{gL}^{-1}$, optimal pseudo order equation $n=1.115$ and constant $K_{n}=1.11 \times 10^{-3} \mathrm{mgg}^{-(1-n)} S^{-1}$, thus a reasonable small value of RSME and MAE also gave a good correlation between the predicted filtrate volume and experimental values. This result confirms the performance and the accuracy of the new model, which is able to describe the adsorption of BSA on PCTE membrane.

Fig. 2 presents the nonlinear regression of the calculated volume versus experimental volume. Overall, the $R^{2}$ values for PSO equation are higher than those of PFO equation but it is the best result of the new model for all the different concentrations.

\subsection{Models Comparison}

For more accuracy, a comparative study has been conducted between the new model (Eq. (12)), the PFO (Eq. (6)) and PSO (Eq. (7)). However, using MATLAB software, the non-linear regression curves of the model and the PFO and PSO equations are shown in Fig. 3.
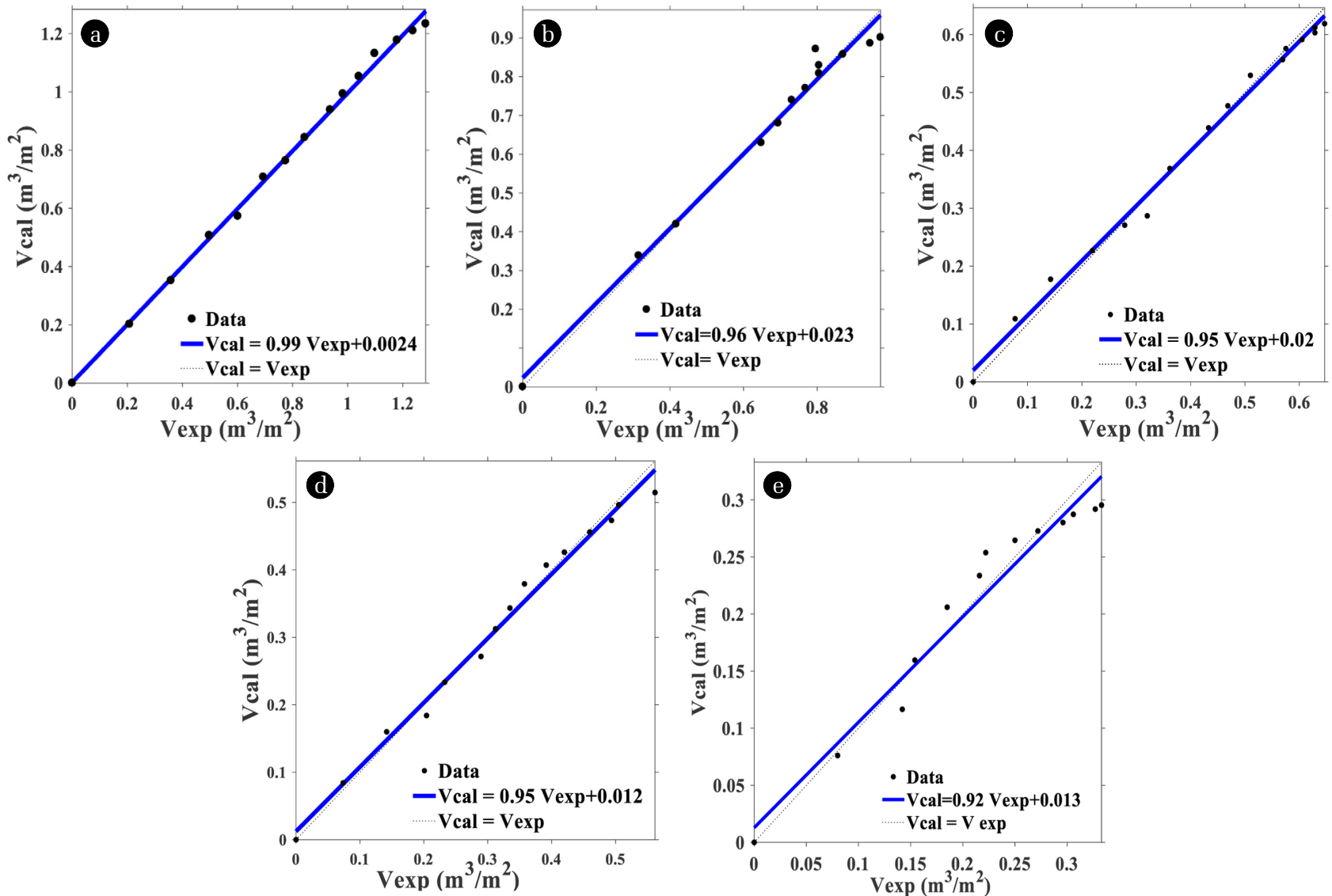

Fig. 2. Nonlinear regression between experimental and calculated volume curves for five experiments (a) $c=0.5 \mathrm{~g} / L$, (b) $c=1.0 \mathrm{~g} / L$, (c) $c=1.4 \mathrm{~g} / L$, (d) $c=2.0 \mathrm{~g} / \mathrm{L}$ and (e) $c=5.0 \mathrm{~g} / \mathrm{L}$. 
Table 3. Kinetic Parameters and Correlation Coefficients for Nonlinear Regression of PFO Equation, PSO and Model Proposed for the Adsorption of BSA on PCTE Membrane for Different Concentration $c=0.5 g L^{-1}, c=1.4 g L^{-1}, c=2.0 g L^{-1}$ and $c=5.0 g L^{-1}$

\begin{tabular}{|c|c|c|c|c|c|}
\hline Concentration & $\mathrm{C}=0.5 g L^{-1}$ & $\mathrm{C}=1.0 g L^{-1}$ & $\mathrm{C}=1.4 g L^{-1}$ & $\mathrm{C}=2.0 g L^{-1}$ & $\mathrm{C}=5.0 g L^{-1}$ \\
\hline $\mathrm{n}_{1}(\mathrm{n}=1)$ & 1 & 1 & 1 & 1 & 1 \\
\hline $\mathrm{n}_{2}(\mathrm{n}=2)$ & 2 & 2 & 2 & 2 & 2 \\
\hline $\mathrm{n}_{\text {optimal }}$ & 1.1450 & 1.5715 & 1.1150 & 1.9561 & 2.0834 \\
\hline $\mathrm{R}_{1}^{2}$ & 0.313 & 0.540 & 0.255 & 0.289 & 0.413 \\
\hline $\mathrm{R}_{2}^{2}$ & 0.978 & 0.975 & 0.972 & 0.989 & 0.952 \\
\hline $\mathrm{R}_{\text {optimal }}^{2}$ & 0.997 & 0.983 & 0.993 & 0.989 & 0.953 \\
\hline $\mathrm{RMSE}_{1}$ & 0.285 & 0.191 & 0.151 & 0.127 & 0.074 \\
\hline $\mathrm{RMSE}_{2}$ & 0.0494 & 0.0413 & 0.0290 & 0.0171 & 0.0225 \\
\hline RMSE $_{\text {optimal }}$ & 0.0208 & 0.0364 & 0.0171 & 0.0171 & 0.0215 \\
\hline $\mathrm{MAE}_{1}$ & 0.501 & 0.298 & 0.364 & 0.378 & 0.446 \\
\hline $\mathrm{MAE}_{2}$ & 0.421 & 0.257 & 0.419 & 0.409 & 0.445 \\
\hline $\mathrm{MAE}_{\text {optimal }}$ & 0.3870 & 0.2690 & 0.3930 & 0.3185 & 0.2141 \\
\hline $\mathrm{k}_{1}\left(\min ^{-1}\right)$ & 5.359 & 8.422 & 5.380 & 3.792 & 3.374 \\
\hline $\mathrm{k}_{2}\left(\operatorname{mg}\left(\operatorname{gmin}^{-2}\right)\right)$ & $8.9110^{-4}$ & $1.6010^{-3}$ & $2.6010^{-3}$ & $3.1010^{-3}$ & $4.4010^{-3}$ \\
\hline $\mathrm{k}_{\text {optimal }} \mathrm{mgg}^{-(1-n)} \mathrm{s}^{-1}$ & $6.6910^{-4}$ & $1.1010^{-3}$ & $1.1010^{-3}$ & $2.9010^{-3}$ & $5.0010^{-3}$ \\
\hline
\end{tabular}
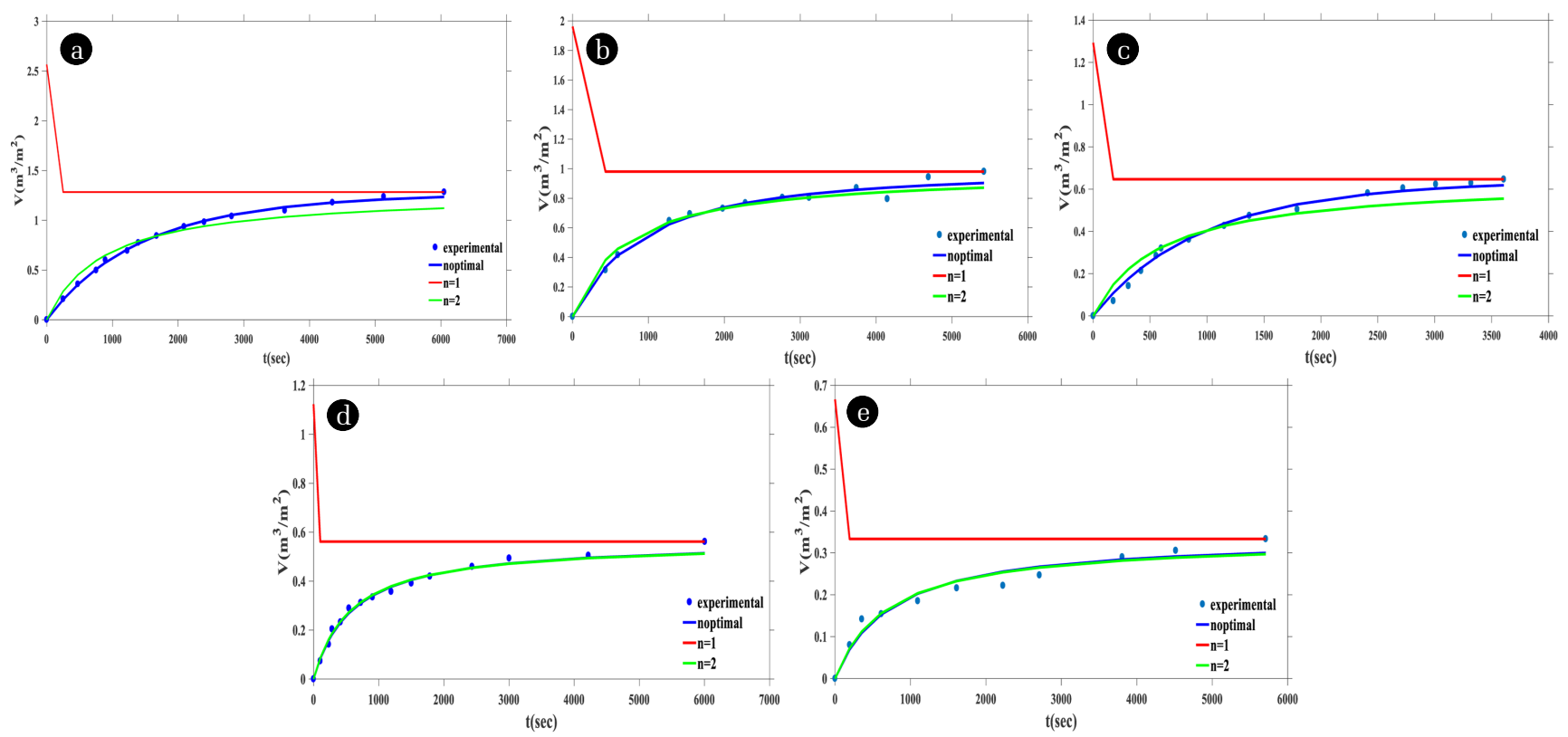

Fig. 3. Adsorption profile of BSA on PCTE membrane plotted for PFO and PSO models during five experiments (a) $c=0.5 \mathrm{~g} / L$, (b) $c=1.0 \mathrm{~g} / L$, (c) $c=1.4 \mathrm{~g} / L$, (d) $c=2.0 \mathrm{~g} / \mathrm{L}$ and (e) $c=5.0 \mathrm{~g} / \mathrm{L}$.

Regression results between the calculated and experimental values of the volume filtrate obtained from the PFO kinetic model did not give reasonable correlation values coefficient $R^{2}$ of $0.255-0.54$ for different concentration of BSA, showing relatively large RMSE values of 0.074-0.28. Consequently, the experimental results did not follow the first-order kinetic model.

Furthermore, for PSO kinetic, the calculated $V_{i, c a l}$ values did not agree with the experimental $V_{i, \exp }$ value, which also gives a relatively large deviation of RMSE 0.0494-0.0171.

However, for the proposed model, the calculated $V_{i, c a l}$ values were consistent with the experimental $V_{i, \exp }$ values, resulting in a relatively small deviation of RMSE $0.0171-0.0364$, in addition to linear regression coefficients, close to 0.997 .

Moreover, the $\mathrm{n}$ values to the largest $R^{2}$ and to the least RMSE are almost identical. The value of $R^{2}$ obtained from the nonlinear regression of the MATLAB software can therefore be used to perfectly judge the best-fit order.

Hence, it can be concluded that the kinetics of BSA adsorption on the PCTE membrane followed the proposed model and the optimal pseudo-order equation confined between 1 and 2 . 


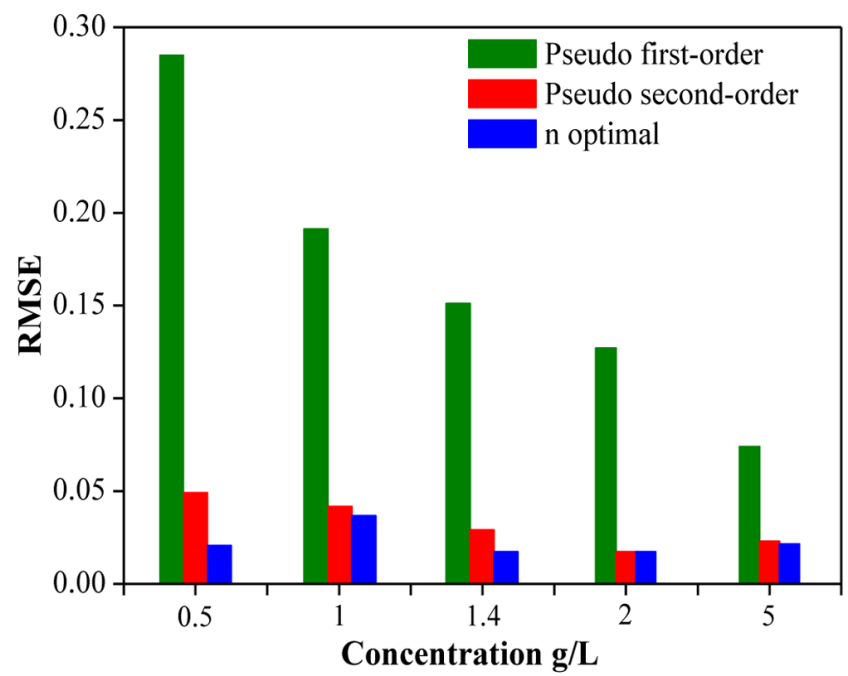

Fig. 4. Comparison of RMSE for pseudo-first-order equation, pseudo-second-order equations and the new model for five experiments $(c=0.5 \mathrm{~g} / L, 1.0 \mathrm{~g} / \mathrm{L}, 1.4 \mathrm{~g} / \mathrm{L}, 2.0 \mathrm{~g} / \mathrm{L}$ and $5.0 \mathrm{~g} / \mathrm{L}$ ).

\subsection{Validation of the Model for Other Experimental Data in the Literature}

To test the capability and validity of the proposed model, it should be possible to study the model parameters for other experimental and measurements to estimate them from correlations. In this respect, it should be collected a data possible in order to better indicate the ability of the proposed model and characterise the profile of the adsorption process. For this purpose we collect a different experimental data, the model for different experimental cases under different conditions operational, filtration mode nature and substance adsorbed. Table 4 summarised the kinetic parameters of adsorption process for different case studies.

Table 4 shows that the best fit orders for adsorption of DNA solution, oil in water emulsion, 2-acrylamido-2- methyl, propane sulfonic acid acrylamide, sodium P-styrenesulfonate were found, respectively $0.9,0.39,0.8$ and 0.865 , and therefore they did not exceed 1. In addition, for human serum and polystyrene, the result was 1.68, thus between 1 and 2. Moreover the values of for the model are better than for PFO and PSO.

For the case studies, the test results show the capability of the

Table 4. Kinetic Parameters of MATLAB Software Results and Correlation Coefficients for Non-Linear Regression Obtained for the Case Studies and Comparison between the New Model, PFO and PSO

\begin{tabular}{|c|c|c|c|c|c|c|c|c|c|c|}
\hline \multirow{3}{*}{ Reference } & \multirow{3}{*}{$\begin{array}{l}\text { Filtrate } \\
\text { nature }\end{array}$} & \multirow{3}{*}{$\begin{array}{l}\text { Filtration } \\
\text { mode }\end{array}$} & \multirow{3}{*}{ Operating condition } & \multicolumn{3}{|c|}{ Model } & \multicolumn{2}{|c|}{$\begin{array}{l}\text { Pseudo first-order } \\
\qquad(\mathrm{n}=1)\end{array}$} & \multicolumn{2}{|c|}{$\begin{array}{l}\text { Pseudo second-order } \\
\qquad(\mathrm{n}=2)\end{array}$} \\
\hline & & & & \multicolumn{7}{|c|}{ Statistical analysis data } \\
\hline & & & & n optimal & $\mathrm{R}^{2}$ & RMSE & $\mathrm{R}^{2}$ & RMSE & $\mathrm{R}^{2}$ & RMSE \\
\hline$[36]$ & $\begin{array}{c}\text { DNA } \\
\text { solution }\end{array}$ & $\begin{array}{c}\text { Membran: } \\
\text { PVDF and PES }\end{array}$ & $\begin{array}{c}\mathrm{A}_{\text {filtration: }} 0.28 \mathrm{~cm}^{2} \\
\mathrm{P}_{\text {operating: }} 30.50 \text { or } 65 \mathrm{kPa} \\
\mathrm{T}:-20 \mathrm{C}^{0} \\
\text { C: } 30 \pm 1 \mu \mathrm{g} / \mathrm{mL}\end{array}$ & 0.90 & 0.995 & 4.59 & 0.329 & 196 & 0.954 & 60.4 \\
\hline$[37]$ & $\begin{array}{c}\text { Oil in } \\
\text { water emulsion }\end{array}$ & $\begin{array}{c}\text { PVDF } \\
\text { membrane }\end{array}$ & $\begin{array}{c}\text { TMP : } 0.5 \text { to } 2 \text { bar } \\
\text { C: } 5,000 \mathrm{ppm} \\
\mu=0.2 \mathrm{~m} / \mathrm{s} .\end{array}$ & 0.39 & 0.998 & $1.410^{-3}$ & $3.610^{-2}$ & 0.16 & 0.995 & $2.310^{-3}$ \\
\hline$[38]$ & PSL & $\begin{array}{c}\text { PCTE } \\
\text { membrane }\end{array}$ & $\begin{array}{c}\mathrm{D}_{\text {particle }}: 0.522 \mu \mathrm{m} \\
\mathrm{D}: 1.05 \mathrm{~g} / \mathrm{cm}^{3} \\
\mathrm{P}_{\text {filtration }}: 98-294 \mathrm{kPa} .\end{array}$ & 0.8 & 0.994 & 36.9 & 0.114 & $3.1410^{-4}$ & 0.96 & 74.6 \\
\hline [39] & $\begin{array}{l}\text { IgG and } \\
\text { NPs }\end{array}$ & $\begin{array}{c}\mathrm{NPN} \\
\text { membrane }\end{array}$ & $\begin{array}{c}\mathrm{C}_{\mathrm{IgG}}: 0.5-5 \mathrm{mg} / \mathrm{mL} \\
\text { Concentrations of } 100 \mathrm{~nm} \\
\mathrm{NPs}: 10^{9} \text { up to } 10^{13} \mathrm{parts} / \mathrm{mL} \text {. } \\
20 \mathrm{~nm} \text { NPs }: 10^{11} \text { to } 10^{15} \text { parts } / \mathrm{mL}\end{array}$ & 1.68 & 0.992 & $810^{-3}$ & 0.572 & 0.065 & 0.990 & 0.009 \\
\hline$[40]$ & $\begin{array}{c}\text { AMPS, } \\
\text { AM and SSS }\end{array}$ & $\begin{array}{l}\text { Water-based } \\
\text { drilling fluid }\end{array}$ & $\begin{array}{c}\mathrm{T}: 160 \mathrm{C}^{0} \\
\mathrm{P}: 0.69 \mathrm{MPa}\end{array}$ & 0.86 & 0.996 & 0.389 & $4.4410^{-16}$ & $6.2710^{-7}$ & 0.981 & 0.0046 \\
\hline
\end{tabular}

PSL : polystylene latex

IgG : from human serum

NPs : polystyrene

AMPS: 2-acrylamido-2-methylpropane sulfonic acid

AM : acrylamide

SSS : sodium p-styrenesulfonate

PVDF : polyvinylidene difluoride

PES : polyether sulfone

PCTE : rack-etched polycarbonate

NPN : nanoporous silicon nitrid 
model, it is concluded that the new model proposed can be extended for practical application.

This current work proposed a simple model to indicate the best-fit kinetic parameters for the adsorption process, which allows us to describe it more accurate than using the convenient model of pseudo-first and second-order.

\section{Conclusions}

The first-order and second-order pseudo models (PFO/PSO) were widely used to describe the kinetic data of liquid/solid adsorption and the expressions of these two models were obtained based on the assumption of ideal operating conditions.

Therefore, in this study, a new model non-linear pseudo $n^{\text {th }}$ order was developed based on a real assumption, to correlate the kinetic data of BSA adsorption on PCTE membrane for different concentrations. MATLAB software was used to optimize the pseudo-order and to describe the kinetic parameters, thus a comparison of PFO, PSO and the proposed model equations for the description of adsorption kinetics has been examined.

The results indicate that the predicted values obtained from the new model are in excellent agreement with the experimental data of adsorption process giving a best correlation coefficient $R^{2}$ up to 0.997 and a reasonable small value of RMSE and MAE, respectively up to 0.0171 and 0.2141 The optimal pseudo order of BSA adsorption on PCTE membrane $n=1.115$ was between 1 and 2; the best-fit curves were plotted for the proposed model.

Depending on the capacity and validity of the model, it should be possible to study the model parameters for other experiments and measurements in order to estimate them from the correlations. In this respect, it should be collected a data possible in order to better indicate the ability of the model proposed and characterize the profile of the adsorption process. Indeed, the model gives the best fit and better correlation coefficient as first-order pseudo and second-order pseudo. Based on this work, the examination of the model parameters will be addressed in other future work.

\section{Acknowledgments}

The authors gratefully acknowledge the Algerian Ministry of Higher Education and Scientific Research (CNEPRU Projects Nos. J0102620110007 and J0102620140015) and Laboratory of Biomaterials and Transport Phenomena (LBMPT) of University Yahia Fares of Medea, Algeria. We would also like to thank the Unit of Solar Equipments Development-UDES/EPST CDER, of Tipaza, Algeria, head of research department, Cooling Systems and Water Treatment using Renewable Energies-FTEER.

\section{Nomenclature}

$\begin{array}{ll}A_{\text {filtration }} & \text { Area filtration }\left(\mathrm{cm}^{2}\right) \\ C_{\text {in }} & \text { Mass substance concentration in feed flow } \\ D & \text { Density }\left(\mathrm{g} / \mathrm{cm}^{3}\right)\end{array}$

$\begin{array}{ll}D_{\text {particle }} & \text { Particle diameter }(\mu \mathrm{m}) \\ K_{n} & \text { Rate constant of reaction }\left(\mathrm{mg} / \mathrm{g}^{(1-n)} \mathrm{s}^{-1}\right) \\ k_{1} & \text { Pseudo first order rate constant of adsorption }\left(\mathrm{min}^{-1}\right) \\ k_{2} & \text { Pseudo second order rate constant of adsorption }(\mathrm{mg} / \mathrm{g} \mathrm{min}) \\ M & \text { Membrane mass }(\mathrm{g}) \\ M A E & \text { Mean relative error } \\ n & \text { Empirical equation order } \\ P_{\text {operating }} & \text { Operating pressure }(\mathrm{KPa}) \\ P_{\text {filtration }} & \text { Filtration pressure }(\mathrm{KPa}) \\ q & \text { Adsorbed amount }(\mathrm{mg} / \mathrm{g}) \\ q_{\text {max }} & \text { Maximum adsorbed amount }(\mathrm{mg} / \mathrm{g}) \\ R^{2} & \text { Regression correlation coefficient } \\ R M S E & \text { Root mean square error } \\ T M P & \text { Transmembrane pressure }(\mathrm{KPa}) \\ V & \text { Filtrate volume }\left(\mathrm{m}^{3} / \mathrm{m}^{2}\right) \\ V_{m} & \text { Maximum filtration volume }\left(\mathrm{m}^{3} / \mathrm{m}^{2}\right) \\ V_{\text {cal }} & \text { Calculated filtration volume of BSA on PCTE membrane } \\ & \left(\mathrm{m}^{3} / \mathrm{m}^{2}\right) \\ V_{\text {exp }} & \text { Experimental filtration volume of BSA on PCTE mem- } \\ & {\text { brane }\left(\mathrm{m}^{3} / \mathrm{m}^{2}\right)}\end{array}$

\section{Greek letters}

$\delta$ Retention rate of membrane

$\mu$ Fluid velocity $(\mathrm{m} / \mathrm{s})$

\section{References}

1. Al-Amoudi AS. Factors affecting natural organic matter (NOM) and scaling fouling in NF membrane: A review. Desalination 2010;259:1-10.

2. Gavach M. Detoxification of reverse osmosis distillery condensates ion exchange and their combination Application to recycling in alcoholic fermentation [dissertation]. Paris: Univ. of Paris Tech; 2010.

3. Shaikh RA, Hamed K, Tomohisa Y, Hideto M, Hiromitsu T, Da-Ming W. Adsorption of bovine serum albumin on poly(vinylidene fluoride) surfaces in the presence of ions: A molecular dynamics simulation. Phys. Chem. J. 2018;122:191-1928.

4. Nakamura K, Matsumoto K. Protein adsorption properties on microfiltration membrane: A comparison between static and dynamic adsorption methods. J. Membr. Sci. 2006;285:126-136.

5. Delmas H, Manole C, Wilhelm AM. AD-OX: A sequential oxidative process for water treatment adsorption and batch CWAO regeneration of activated carbon. Chem. Eng. J. 2009;152: 189-194.

6. Tan KL, Hameed BH. Insight into the adsorption kinetics models for the removal of contaminants from aqueous solutions. J. Taiwan Inst. Chem. Eng. 2017;74:25-48.

7. Lagergren S. Zur theorie der sogenannten adsorption geloster stoffe, Kungliga Svenska Vetenskapsakademiens. Handlingar 1928;24:1-39.

8. Blanchard G, Maunaye M, Martin G. Removal of heavy metals from waters by means of natural zeolites. Water Res. 1984;18:1501-1507. 
9. Gosset T, Trancart JL, Thévenot DR. Batch metal removal by peat: Kinetics and thermodynamics. Water Res. 1986;20:21-26.

10. Ho YS. Second-order kinetic model for the sorption of cadmium onto tree fern: A comparison of linear and non-linear methods. Water Res. 2006;40:119-125.

11. Kumar KV, Sivanesan S. Selection of optimum sorption kinetics: Comparison of linear and non-linear methods. J. Hazard. Mater. 2006;134:277-279.

12. Ho YS, Ofomaja AE. Kinetic studies of copper ion adsorption on palm kernel fiber. J. Hazard. Mater. 2006;137:1796-1802.

13. Fang F, Satulovsky J, Szleifer I. Kinetics of protein adsorption and desorption on surfaces with grafted polymers. Biophys. J. 2005;89:1516-1533.

14. Simonin JP. On the comparison of pseudo-first order and pseudo-second order rate laws in the modeling of adsorption kinetics. Chem. Eng. J. 2016;300:254-263.

15. Xiao CW, Liu XJ, Mao SM, Zhang LJ, Lu J. Sub-micron-sized polyethylenimine modified polystyrene/Fe3O4/chitosan magnetic composites for the efficient and recyclable adsorption of $\mathrm{Cu}(\mathrm{II})$ ions. Appl .Surf. Sci. 2017;394:378-385.

16. Chen J, Shi X, Zhan Y, Qiu X, Du Y, Deng H. Construction of horizontal stratum landform-like composite foams and their methyl orange adsorption capacity. Appl. Surf. Sci. 2017;397: 133-143.

17. Tu H, Huang MT, Yi Y, et al. Chitosan-rectorite nanospheres immobilized on polystyrene fibrous mats via alternate electrospinning/electrospraying techniques for copper ions adsorption. Appl. Surf. Sci. 2017;426:545-553.

18. Huang MT, Tu H, Chen J, et al. Chitosan-rectorite nanospheres embedded aminated polyacrylonitrile nanofibers via shoulder-to-shoulder electrospinning and electrospraying for enhanced heavy metal removal. Appl. Surf. Sci. 2018;437:294-303.

19. Tseng RL, Wua PH, Feng CW, Ruey SJ. A convenient method to determine kinetic parameters of adsorption processes by nonlinear regression of pseudo-nth-order equation. Chem. Eng. 2014;237:153-161.

20. Xu TW, Fu RQ, Yan LF. A new insight into the adsorption of bovine serum albumin onto porous polyethylene membrane by zeta potential measurements, FTIR analysis and AFM observations. J. Colloid. Interf. Sci. 2003;262:342-350.

21. Anirudhan TS, Tharun AR, Rejeena SR. Investigation on poly (methacrylic acid)-grafted cellulose/bentonite superabsorbent composite: Synthesis, characterization, and adsorption characteristics of bovine serum albumin. Ind. Eng. Chem. Res. 2011;50:1866-1874.

22. Wang Z, Yue T, Yuan Y, Cai R, Niu C, Guo C. Kinetics of adsorption of bovine serum albumin on magnetic carboxymethyl chitosan nanoparticles. Int. J. Biol. Macromol. 2013;58:57-65.

23. Sasidharan NP, Chandran P, SudheerKh S. Interaction of colloidal zinc oxide nanoparticles with bovine serum albumin and its adsorption isotherms and kinetics. Colloid. Surf. B: Biointerf. 2013;102:195-201.

24. Devillers J. Neural network in QSAR and drug design. 1st ed.
San Diego: Academic Press; 1996.

25. Zupan J, Gasteiger J. Neural networks in chemistry and drug design. 2nd ed. Weinheim: Wiley-VCH VerlagGmbh; 1999.

26. Fu RQ, Xu TW, Pan ZX. Modeling of the adsorption of bovine serum albumin on porous polyethylene membrane by back-propagation artificial neural network. J. Membr. Sci. 2005;251:137-144.

27. Ho CC, Zydney AL. A combined pore blockage and cake filtration model for protein fouling during microfiltration. J. Colloid. Interf. Sci. J. 2000;232:389-399.

28. Tien C, Ramarao B. Revisiting the laws of filtration: An assessment of their use in identifying particle retention mechanisms in filtration. Membr. Sci. J. 2011;383:17-25.

29. Ho YS, McKay G. A comparison of chemisorption kinetic models applied to pollutant removal on various sorbents. Proc. Saf. Environ. J. 1998;76:332-340.

30. Ho YS, McKay G. Comparative sorption kinetic studies of dyes and aromatic compounds onto fly ash. J. Environ. Sci. Health Part A 1999;34:1179-1204.

31. Ho YS, McKay G. The kinetics of sorption of divalent metal ions onto sphagnum moss peat. Water Res. 2000;34:735-742.

32. Dastkhoon M, Mehrorang G, Arash A, Azqhandi MHA, Purkait MK. Simultaneous removal of dyes onto nanowires adsorbent use of ultra-round assisted adsorption to clean wastewater chemometrics for modeling and optimization, multicomponent adsorption and kinetics study. Chem. Eng. Res. Des. 2017;124: 222-237.

33. Foo KY, Hameed BH. Insights into the modeling of adsorption isotherm systems. Chem. Eng. J. 2010;156:2-10.

34. Mall ID, Srivastava VC, Agarwal NK. Removal of orange-G and methyl violet dyes by adsorption onto bagasse fly ash-kinetic study and equilibrium isotherm analyses. Dyes Pigm. 2006;69:210-223.

35. Vishnuvardhan TR, Sachin C, Saswati C. Adsorption isotherm and kinetics analysis of hexavalent chromium and mercury on mustard oil cake. Environ. Eng. Res. 2017;22:95-107.

36. Kong S, Aucamp J, Titchener-Hooker NJ. Studies on membrane sterile filtration of plasmid DNA using an automated multiwell technique. J. Membr. Sci. 2010;353:144-150.

37. Fouladitajar A, Ashtiani FZ, Okhovat A, Dahir B. Membrane fouling in microfiltration of oil in water emulsion; comparison between constant pressure blocking laws and genetic programming (GP) model. Desalination 2013;329:41-49.

38. Iritani E, Nobuyuki K, Takenaka T, Yamashita Y. Membrane pore blocking during cake formation in constant pressure and constant flux dead-end microfiltration of very dilute colloids. Chem. Eng. Sci. 2015;122:465-473.

39. Winans JD, Smith KJP, Gaborski TR, Roussie JA, McGrath JL. Membrane capacity and fouling mechanisms for ultrathin nanomembranes in dead-end filtration. J. Membr. Sci. 2016;499: 282-289.

40. Huo JH, Peng ZG, Ye ZB, et al. Investigation of synthesized polymer on the rheological and filtration performance of water based drilling fluid system. J. Petrol. Sci. Eng. 2018;165:655-663. 